7. Reprod. Fert. (1967) 13, 361-364

BRIEF COMMUNICATION

\title{
SPECIES-SPECIFICITY OF SPERM CAPACITATION IN THE RABBIT
}

\author{
J. M. BEDFORD* AND RUTH SHALKOVSKY \\ Department of Physiology, Royal Veterinary College, London
}

(Received 1st November 1966)

The most important aspect of the relationship between mammalian spermatozoa and the female tract to be revealed so far is the process of capacitation, which finally confers upon spermatozoa their ability to fertilize (Austin, 1951; Chang, 1951). The changes which take place in spermatozoa in the female tract, as a concomitant of capacitation, remain uncertain. One approach to this problem lies in identification of the environmental factors necessary for capacitation. It has been claimed that rabbit spermatozoa may be capacitated in the bladder, colon and anterior chamber of the eye (Noyes, Walton \& Adams, 1958 ), and by incubation in vitro with uterine fluids or with $\beta$-amylase (Kirton $\&$ Hafs, 1965). In these investigations, however, fertilizing ability was assessed by sperm deposition into the oviducts soon after ovulation. This must leave doubt as to whether capacitation was completed outside the female tract.

As nothing is known of the species-specificity requirement for complete functional capacitation, in the present study attempts have been made to capacitate rabbit spermatozoa in the cat, ferret, guinea-pig and the rat. Approximately 4 to 8 million epididymal rabbit spermatozoa in $0.03 \mathrm{ml} \mathrm{Hanks'}$ solution were inseminated in oestrous cats, ferrets, guinea-pigs and rats into each uterine horn, which was then ligated close to the cervix. Rabbit spermatozoa survived for not more than $12 \mathrm{hr}$ in the cat, ferret and guinea-pig, and spermatozoa removed before this time did not fertilize any eggs when deposited into the rabbit oviduct soon after ovulation. In the uterus of oestrous rats, however, rabbit spermatozoa sometimes survived for up to $48 \mathrm{hr}$ (Bedford, 1967). The following results suggest that some, but not all, phases of capacitation of rabbit spermatozoa may be accomplished in the rat uterus.

In the first experiments, rats were inseminated as described above. Motile rabbit spermatozoa were later recovered in uterine fluids between $5 \frac{1}{4}$ and $18 \mathrm{hr}$ after insemination, and 31 to $550 \times 10^{3}$ in $0.025 \mathrm{ml}$ were placed in the oviduct of rabbits, 12 to $13 \mathrm{hr}$ after an ovulation injection. The tubal ova were recovered 10 to $24 \mathrm{hr}$ later. With the exception of one fertilized at $9 \mathrm{hr}$, no ova were penetrated by spermatozoa which had resided for less than $14 \mathrm{hr}$ in the rat

* Present address: The Worcester Foundation for Experimental Biology, 222 Maple Avenue, Shrewsbury, Massachusetts, U.S.A. 
uterus (Table 1). Rabbit spermatozoa which had been in the rat uterus for more than $14 \mathrm{hr}$, on the other hand, fertilized a significant proportion of tubal ova.

These results seemed to indicate that rabbit spermatozoa may be capacitated in the uterus of the rat, though in the latter environment capacitation is obviously achieved more slowly than in the rabbit uterus (Adams \& Chang, 1962). The completeness of capacitation of rabbit spermatozoa in the rat uterus was brought into doubt, however, as a considerable number of ova in some animals were not fertilized by spermatozoa which had been in the rat for more than $15 \mathrm{hr}$, though large numbers of spermatozoa were present on the zona surface of these unfertilized eggs. Furthermore, in those eggs fertilized, very rarely were supplementary spermatozoa seen in the perivitelline space.

TABLE 1

FERTILIZING ABILITY OF RABBIT SPERMATOZOA REGOVERED AFTER RESIDING FOR DIFFERENT LENGTHS OF TIME IN THE UTERUS OF THE OESTROUS RAT

\begin{tabular}{|c|c|c|c|c|c|c|}
\hline \multirow{2}{*}{$\begin{array}{l}\text { Time of sperm. } \\
\text { residence in } \\
\text { the rat uterus } \\
(\mathrm{hr})\end{array}$} & \multirow[t]{2}{*}{$\begin{array}{l}\text { No. } \\
\text { expts }\end{array}$} & \multirow{2}{*}{$\begin{array}{c}\text { No. sperm. } \\
\text { insem./oviduct } \\
\times 10^{3} \\
(\text { range })\end{array}$} & \multicolumn{2}{|c|}{$\begin{array}{l}\text { Experimental animal: } \\
\text { Sperm. insem. } 12-13 \mathrm{hr} \\
\text { after ovulating injection }\end{array}$} & \multicolumn{2}{|c|}{$\begin{array}{l}\text { Control animal: } \\
\text { Sperm. insem. } 0-5 \mathrm{hr} \\
\text { after ovulating injection }\end{array}$} \\
\hline & & & Ova recovered & $\%$ Fertilized & Ova recovered & $\%$ Fertilized \\
\hline $\begin{array}{l}5 \frac{1}{4} \\
6 \frac{1}{4} \\
91 \\
10 \frac{1}{2} \\
12 \frac{1}{2} \\
14 \\
15 \\
17-17 \frac{1}{2} \\
18-18 \frac{1}{2}\end{array}$ & $\begin{array}{l}1 \\
1 \\
1 \\
1 \\
4 \\
3 \\
3 \\
3 \\
3\end{array}$ & $\begin{array}{c}200-350 \\
50-100 \\
100-200 \\
100-220 \\
31-350 \\
45-60 \\
50 \\
60-465 \\
32-550\end{array}$ & $\begin{aligned} 6 & (2) \\
5 & (1) \\
4 & (1) \\
6 & (1) \\
41 & (4) \\
26 & (3) \\
23 & (3) \\
16 & (3) \\
31 & (4)\end{aligned}$ & $\begin{array}{r}0 \\
0 \\
25 \\
0 \\
0 \\
3 \\
48 \\
94 \\
32\end{array}$ & $\begin{aligned} 13 & (1)^{*} \\
5 & (1) \\
7 & (1) \\
5 & (1) \\
7 & (2) \\
& - \\
8 & (1) \\
18 & (3) \\
9 & (2)\end{aligned}$ & $\begin{array}{r}100 \\
20 \\
100 \\
60 \\
70 \\
- \\
50 \\
90 \\
88\end{array}$ \\
\hline
\end{tabular}

* Number of animals in parentheses.

This question was tested critically as follows: rabbit spermatozoa recovered from the rat uterus after 20 to $24 \mathrm{hr}$ were washed and resuspended in rabbit uterine flushings; sperm samples obtained at the same time from the rabbit uterus, $12 \mathrm{hr}$ after natural mating, were concentrated by light centrifugation. Sperm recovered from the rat uterus were then introduced into one oviduct, and those recovered from the rabbit uterus were inseminated likewise into the contralateral tubal ampulla $13 \frac{3}{4}$ to $14 \frac{1}{2} \mathrm{hr}$ after an ovulation injection (approximately $\frac{1}{2}$ to $2 \frac{1}{2} \mathrm{hr}$ before termination of the fertile life of the ovum). Aliquots of the rat-incubated rabbit spermatozoa were also inseminated intra-tubally into control females only 0.5 to $5.0 \mathrm{hr}$ after an ovulation injection. In spite of some advantage both in time and in numbers, spermatozoa recovered from the rat uterus fertilized only $3.4 \%$ of fifty-eight ova, compared with $45.5 \%$ of forty-four ova fertilized in the contra-lateral tube by spermatozoa capacitated in the rabbit uterus (Table 2).

These results indicate that rabbit spermatozoa living in the rat uterus for up to $26 \mathrm{hr}$ do not have the same immediate capacity for fertilization as those resident for a shorter period in the rabbit uterus. The poor fertility of the rat-incubated samples cannot have been due to loss of their physiological 


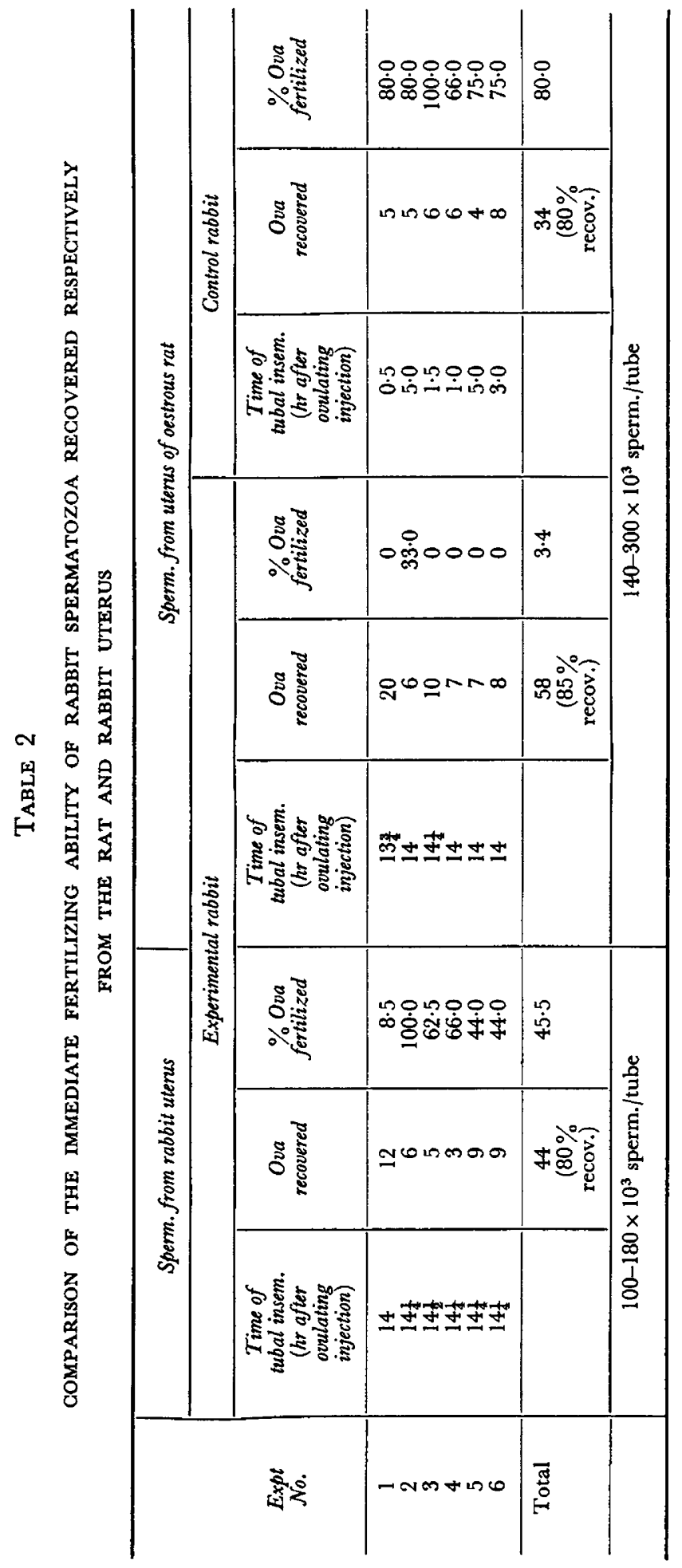


integrity in the foreign environment of the rat, since they fertilized a high percentage of ova in the control females, in which ovulation was relatively delayed. The fertilization failure following late intra-tubal insemination of spermatozoa recovered from the rat was probably because these spermatozoa had not yet become completely capacitated, and further because this state could not then be achieved in the rabbit oviduct before the end of the fertile life of the waiting ova.

As capacitation in the rabbit oviduct alone requires at least $10 \mathrm{hr}$ (Adams \& Chang, 1962), it has been accepted that rabbit spermatozoa must have already been capacitated, if they are to fertilize when inseminated intratubally soon after ovulation. The danger of using this sole criterion becomes evident in the present study; for, taken at face value, the results in Table 1 might suggest that capacitation of rabbit spermatozoa can be completed in the rat. Taken together, however, the present experiments indicate that capacitation is not an all-or-none phenomenon, and probably involves more than one type of change. It therefore seems desirable that in capacitation experiments fertilizing ability should be assessed in vitro, or late in the fertile life of the ovum when intra-tubal insemination is used.

In conclusion, there appears to be considerable species variation in the ability of the uterine milieu to support the metabolism of foreign spermatozoa. For example, rabbit spermatozoa survived for a shorter period in the uterus of some species than in simple physiological media in vitro. This suggests the existence of uterine substances which in some instances are positively harmful to heterologous spermatozoa. Bearing in mind studies in which spermatozoa have been placed in ectopic sites (Noyes et al., 1958) or have been incubated with enzymes in vitro (Kirton \& Hafs, 1965), it seems possible that some phase of capacitation may be brought about by agents which are neither species nor organ specific. The present findings indicate, however, that while part of the capacitation of rabbit spermatozoa can be achieved in the rat uterus, functional capacitation involves another phase which is species specific, and which may possibly be restricted to the female tract.

This work was supported in part by NIH grant No. HD 01476-06.

\section{REFERENCES}

Austin, C. R. (1951) Observations on the penetration of the sperm into the mammalian egg. Aust. F. sci. Res. B, 4, 581 .

Adams, C. E. \& Chang, M. C. (1962) Capacitation of rabbit spermatozoa in the Fallopian tube and in the uterus. 7. exp. Zool. 151, 159.

Bedford, J. M. (1967) Prolongation of the fertile life of rabbit spermatozoa in the rat uterus. Nature, Lond. (In press).

Chang, M. G. (195I) The fertilizing capacity of spermatozoa deposited into the Fallopian tubes. Nature, Lond. 168, 697.

Kirton, K. T. \& Hafs, H. D. (1965) Sperm capacitation by uterine fluid or $\beta$-amylase in vitro. Science, $150,618$.

Noyes, R. W., Walton, A. \& AdAms, C. E. (1958) Capacitation of rabbit spermatozoa. F. Endocr. 17, 374. 